\title{
Curriculo e ensino de matemática: o ábaco como recurso didático visando uma aprendizagem significativa
}

\section{Curriculum and Mathematics Teaching: the Abacus as a Didactic Resource Aiming at Meaningful Learning}

\author{
José Ronaldo Melo ${ }^{1 *}$
}

\begin{abstract}
RESUMO
Esse artigo tem como objetivo discutir, do ponto de vista teórico, questionamento presentes durante o processo de planejamento do ensino de matemática nas séries iniciais, dentre eles, a maneira mais adequada de se abordar as operações básicas e como tornar esses conceitos utilizáveis na vida diária. Apresenta uma proposta de atividade com a utilização do ábaco que pode tornar o processo de aprendizagem significativa para o aluno, despertando o interesse pela resolução de problemas envolvendo os números naturais. Tratase de uma pesquisa qualitativa, com reflexões a partir da literatura disponível sobre o currículo. Como resultados sugere-se ao professor a utilização do ábaco no ensino das operações básicas envolvendo os números naturais, superando procedimentos padronizados, próprios de uma didática desvinculada de situações reais, contribuindo assim, para uma nova relação do aluno com o conhecimento adquirido através de resolução de problemas.
\end{abstract}

Palavras-chave: Ensino de Matemática; Resolução de problemas; Materiais curriculares; Aprendizagem.

\begin{abstract}
This article aims to discuss, from a theoretical point of view, questions present during the planning process of teaching mathematics in the early grades, among them, a more adequate way to approach the basic operations and how to make these concepts usable na daily life. It presents an activity proposal with the use of the abacus that can make the learning process closer to the student, arousing interest in solving problems involving natural numbers. This is qualitative research, with reflections based on the available literature on the curriculum. As mandatory results, the teacher is required to use the abacus in teaching basic operations involving natural numbers, surpassing standard procedures, typical of a didactic unrelated to real hypotheses, thus contributing to a new relationship between the student and the knowledge acquired through resolution of problems.
\end{abstract}

Keywords: Mathematics Teaching; Problem solving; Curriculum materials; Learning.

\footnotetext{
${ }^{1}$ Universidade Federal do Acre (UFAC); Centro de Ciências Exatas e Tecnológicas (CCET)

*E-mail: Ronaldo.ufac@gmail.com
} 


\section{INTRODUÇÃO}

Apresento neste artigo discussões sobre o desenvolvimento do currículo no processo de Ensino de Matemática, sugerindo uso do ábaco no ensino de operações básicas dos números naturais, normalmente desenvolvida em sala de aula nas séries iniciais do Ensino Fundamental. Para isso, faço uso de reflexões provenientes da literatura que aborda, do ponto de vista histórico, o desenvolvimento do currículo no Ensino de Matemática com recursos didáticos manipuláveis, sobretudo o uso do ábaco, como uma estratégia para o desenvolvimento do ensino desse importante componente curricular no sistema escolar.

Objetivo, portanto, investigar se no desenvolvimento do currículo, o ábaco pode se constituir em um recurso que possa favorecer a aprendizagem dos alunos em relação às operações básicas com os números naturais. Assim, acredito ser importante conhecer um pouco acerca da História da Matemática e da Matemática, ciência em que o ábaco é utilizado como instrumento didático, bem como se esse instrumento traz algum benefício que possa influenciar, direta ou indiretamente, a aprendizagem matemática.

Assim, apresento uma breve passagem pela História da Matemática, enfatizando o pré-conceito que ronda esta ciência e que a coloca como a mais difícil disciplina com a qual o aluno deve lidar desde os seus primeiros passos na vida estudantil até a academia. Apresento também dificuldades, desafios e possibilidades para o ensino dessa disciplina.

Como relata D’Ambrósio (2011), o conhecimento matemático é produto de diferentes conhecimentos empíricos desenvolvidos pelas civilizações ao longo da história, por meio das relações que o homem estabelecia entre si, com a natureza e a sociedade, na busca pela sobrevivência, conhecimentos estes, sistematizados e difundidos de geração a geração.

Para o autor referido, se a Matemática ensinada nas escolas resulta dessa ciência que surgiu de experiências cotidianas do ser humano, acredita-se que é importante que ela seja ministrada a partir das experiências vivenciadas pelos estudantes em seu cotidiano, desde as mais simples, como classificar, seriar, contar, comparar quantidades e realizar operações entre essas quantidades, com vistas à apropriação do conhecimento sistematizado ao longo do desenvolvimento humano.

Destacamos que Vigotski (1978) desenvolveu uma teoria sobre a aprendizagem tomando como ponto de partida o fato de que ela acontece muito antes de o estudante 
entrar na escola, por meio das relações entre as pessoas, o que promove o seu desenvolvimento. Para esse autor o processo de aprendizagem, o desenvolvimento e o ensino, sempre se mostraram relevantes e para ele o entendimento de como se processa a relação entre instrução escolar e desenvolvimento cognitivo é um dos passos para se adentrar ao cerne da questão desenvolvimental do indivíduo. Argumenta ainda que a maneira como os adultos buscam transmitir para as crianças os seus modos, seus pensamentos, suas experiências e sua cultura, demonstram que desde cedo estas já estão em interação constante com os adultos e que, em consequência disso os processos cognitivos e psicológicos mais complexos vão tomando forma, explicando que:

Cada função no desenvolvimento cultural de uma criança aparece duas vezes: primeiro no nível social e mais tarde, no nível individual, primeiro entre pessoas (interpsicológico) e depois dentro da criança (intrapsicológico). Isso se aplica igualmente a toda atenção voluntária, à memória, à formação de conceitos. Todas as ações mentais superiores se originam como relações reais entre pessoas. (VYGOTSKY, 1978, p.57).

Concordando com este pensamento acredito que a aprendizagem da criança começa muito antes da aprendizagem escolar. Ao chegar na escola o aluno já traz uma história e, neste sentido, a aprendizagem não necessariamente se inicia na idade escolar, o que significa afirmar que há uma diferença substancial entre o que é produzido em termos de aprendizagem antes da criança estar na idade escolar e o que ela adquire durante sua estada nas instituições escolares.

Como expressa Silva (2014), o universo desafiador de todo educador se reflete no compromisso deste com a educação, o qual, por sua vez, se reflete nos conteúdos, na responsabilidade com os alunos e nos processos de ensino e aprendizagem, nos desafios, metas e objetivos que se impõem em meio ao contexto social escolar e, neste contexto de desafios, a organização do ensino se concretiza diariamente, pois há que se organizar um ensino que considere todos estes desafios, inclusive neste conhecimento que o aluno já traz.

Conforme orienta as Diretrizes Curriculares da Educação Básica para Matemática além de diferenciadas metodologias, outras questões, como a avaliação, por exemplo, são importantes, cabendo à escola:

(...) incentivar a prática pedagógica fundamentada em diferentes metodologias, valorizando concepções de ensino, de aprendizagem (internalização) e de avaliação que permitam aos professores e estudantes conscientizarem-se da necessidade [...] um projeto educativo, nessa direção, precisa atender igualmente aos sujeitos, seja 
qual for sua condição social e econômica, seu pertencimento étnico e cultural e às possíveis necessidades especiais para aprendizagem (PARANÁ, 2008, p.15).

Essas características que vêm sendo a muito discutidas no âmbito educacional são discursos que defendem uma educação de qualidade, voltada para a realidade do aluno e, por isso, significativa, rompendo com a grande distância entre a realidade e a aprendizagem.

\section{CONTEXTOS E ASPECTOS HISTÓRICOS}

Um esboço do desenvolvimento histórico da matemática é delineado por Boyer (1996) ao afirmar que boa parte do que hoje se chama de Matemática tem sua origem nas ideias primitivas centradas nos conceitos de números, grandeza e forma. Conforme esse autor, definições antiquadas da matemática como uma ciência do número e da grandeza já não a contempla mais, não sendo, portanto, mais válidas.

Neste contexto, Boyer (1996) afirma ser somente a partir do século XIX que a Matemática se liberta das limitações sugeridas pelas observações da natureza, muito embora este afirma que, originalmente a Matemática surgiu como parte do cotidiano do homem e, se há validade no princípio biológico "da sobrevivência do mais apto" a persistência da raça humana tem estreita relação com o desenvolvimento no homem de conceitos matemáticos.

Boyer (1996) argumenta ser a linguagem essencial no surgimento do pensamento matemático abstrato e relata, ainda, que as palavras que exprimem idéias numéricas foram aparecendo de forma gradativa, sendo os símbolos para números, antecessores das palavras para números, mas, o fato é que este relata que milhares de anos se passaram até que o homem fizesse distinção entre os conceitos abstratos e repetidas situações concretas evidenciando as dificuldades experienciadas até o estabelecimento de uma base, embora que ainda muito primitiva.

Ainda, com relação à sua origem, sendo uma das premissas a de que usualmente surgiu em resposta às necessidades práticas, embora estudos antropológicos defendam outra origem, sugerindo que a arte de contar surge em conexão com rituais religiosos primitivos, e que o aspecto ordinal precedeu o conceito quantitativo e, destaca que se são corretas as teorias que dão origem ritual à contagem, o conceito de número ordinal pode ser anterior ao conceito de número cardinal. 
Boyer (1996) relata, ainda, que o conceito de número inteiro é o mais antigo na Matemática e sua origem se perde na antiguidade pré-histórica e relata serem as afirmações acerca das origens da Matemática, seja da aritmética, seja da geometria, arriscadas, em razão de ser os primórdios do assunto mais antigos que a arte de escrever, sendo somente nos seis últimos milênios que o homem se mostrou capaz de pôr seus registros e pensamentos em forma escrita, sendo que para informações sobre a pré-história depende-se de interpretações baseadas nos poucos achados históricos, como os artefatos que restaram de evidência fornecida pela moderna antropologia, além de extrapolação retroativa conjectural, a partir de documentação que sobreviveu ao tempo.

\section{A EDUCAÇÃO MATEMÁTICA}

A Educação Matemática como área prioritária que faz parte do campo da Educação é um advento que se dá somente na transição do século XIX para o século XX em uma caminhada que se abre a partir do pensador norte americano John Dewey. Como argumenta Miguel (2004):

Os passos que abrem essa nova área de pesquisa são devidos a John Dewey (1859-1952), ao propor, em seu livro Psicologia do Número (1895), uma reação contra o formalismo e uma relação não tensa, mas cooperativa, entre aluno e professor e uma integração entre todas as disciplinas (MIGUEL, 2004, p.71).

Depois desta iniciativa de John Dewey, em 1902, outra importante iniciativa traz a Educação Matemática para o debte:

O respeitadíssimo matemático americano Eliakim H. Moore (18621932) resolve escrever sobre educação e, num artigo de 1902, propõe um novo programa, incluindo um sistema de instrução integrada em matemática e física, baseado em um laboratório permanente, cujos principais objetivos são desenvolver ao máximo o verdadeiro espírito de pesquisa, conduzindo à apreciação, tanto prática como teórica, dos métodos fundamentais da ciência (MIGUEL, 2004, p.71).

Contudo, o passo mais importante nesta trajetória é destacado por Miguel como uma iniciativa do matemático alemão Felix Klein:

O passo mais importante no estabelecimento da educação matemática como uma disciplina é devido à contribuição do eminente matemático alemão Felix Klein (1849-1925), que publicou, em 1908, um livro seminal, matemática elementar de um ponto de vista avançado. Klein defende uma apresentação nas escolas que se atenha mais a bases psicológicas que sistemáticas. Diz que o professor deve, por assim dizer, ser um diplomata, levando em conta o processo psíquico do aluno, para poder agarrar seu interesse. Afirma que o professor só terá 
sucesso se apresentar as coisas de uma forma intuitivamente compreensível (MIGUEL, 2004, p.71-72).

Entretanto, como esclarece este autor, a consolidação da Educação Matemática como uma subárea da Matemática e da Educação, de natureza interdisciplinar, se dá com a fundação, durante o Congresso Internacional de Matemáticos, realizado em Roma, em 1908, da Comissão Internacional de Instrução Matemática, conhecida pelas siglas IMUK/ICMI, sob liderança de Felix Klein.

\section{A TRAJETÓRIA DA MATEMÁTICA NO BRASIL}

Desde o descobrimento, o ensino no Brasil foi quase uma prerrogativa dos padres da Companhia de Jesus, primeiro grupo de jesuítas que chegou ao Brasil em 1549, junto com o primeiro governador-geral, Tomé de Souza. Ao enviar os jesuítas para a Colônia brasileira, a Coroa portuguesa visava atender aos objetivos do Projeto Português de colonização das terras brasileiras, cuja intenção era converter o índio à fé católica por intermédio da catequese e do ensino de ler e escrever português, considerando, pois, que o instrumento de ajustamento cultural usado pela colonização foi, sobretudo, a ação do jesuíta, este mandado pelo príncipe, irmanado aos homens, aos projetos e ideologia do governo (GOMES. 2012).

Portanto, a salvação, de que ele era portador, vinha do alto, em duas plataformas: a real e a divina e a crença arraigada de que ambas eram inseparáveis, moldou os resultados de todo o seu trabalho de evangelização, do qual dependia o êxito da arrojada empresa colonizadora, pois somente pela aculturação sistemática e intensiva do elemento indígena aos valores espirituais e morais da civilização ocidental e cristã é que a colonização portuguesa poderia lançar raízes definitivas (SHIGUNOV NETO; MACIEL, 2008).

Como destaca Gomes (2012), nas escolas elementares, quanto aos conhecimentos matemáticos, contemplava-se o ensino da escrita dos números no sistema de numeração decimal e o estudo das operações de adição, subtração, multiplicação e divisão de números naturais e, nos colégios, o ensino ministrado era de nível secundário, voltado para uma formação em que o lugar principal era destinado às humanidades clássicas, havendo grande destaque para o latim em detrimento dos conhecimentos matemáticos.

Este autor nos dá ciência, ainda, de que há pouco conhecimento acerca dos conhecimentos matemáticos, sabendo-se somente de que a biblioteca do colégio dos 
jesuítas no Rio de Janeiro possuía muitos livros de Matemática, mas, no entanto, alguns estudos nos levam a ideia geral de que os estudos matemáticos eram realmente pouco desenvolvidos no ambiente jesuíta, se privilegiando mais a catequização.

De conformidade com as informações de Gomes (2012), em 1759, Sebastião José de Carvalho e Melo, o marquês de Pombal, primeiro-ministro de Portugal no período 1750-1777, ordenou a expulsão dos jesuítas de todas as colônias, o que levou ao fechamento de algumas escolas. Pois, estes eram os responsáveis pela maior parte das instituições educacionais no Brasil e das instituições de ensino militar e que a retirada dos jesuítas se constitui em um marco importante na história da educação brasileira, a qual vem passar por outra grande mudança em 1772.

Com o alvará do marquês de Pombal criando as "aulas régias", nas quais isoladamente se ensinaram primeiramente a gramática, o latim, o grego, a filosofia e a retórica e, somente algum tempo depois, as disciplinas matemáticas: aritmética, álgebra e geometria, cujas aulas eram avulsas, e, em relação aos conhecimentos matemáticos, os indícios apontam para poucos alunos e para a dificuldade de se encontrar professores.

Já no final do século XVIII, no que diz respeito ao destaque à Matemática e às ciências, teve a criação do Seminário de Olinda pelo bispo de Pernambuco, Dom Azeredo Coutinho, em 1798, a qual funcionou a partir de 1800 e não formava somente padres, vindo a ser uma das melhores escolas secundárias do Brasil, conferindo, assim, importância ao ensino dos temas matemáticos e científicos.

Contudo, somente com a chegada de D. João VI e da Corte ao Brasil, em 1808, é que houve mudanças em muitos campos, entre estes os ligados à educação e à cultura em geral, sendo muitas instituições culturais e educacionais implantadas, como a Academia Real de Marinha (1808), no Rio de Janeiro, a Academia Real Militar (1810), também no Rio, destinadas a formar engenheiros civis e militares; oferecendo também cursos de cirurgia, agricultura e química, a Escola Real de Ciências, Artes e Ofícios (1816), o Museu Nacional, no Rio de Janeiro, entre outras.

Essas mudanças decorreram, principalmente, do fato de que a Corte, acostumada ao luxo, precisava adequar o ambiente aos seus moldes, já que o ambiente do rio de Janeiro era pobre, com casarios sombrios, sem muitas distrações e pouca cultura. Por outro lado, os habitantes do Rio de Janeiro com esta proximidade da corte e da nobreza, sofreram um processo de aculturamento maior, pois com a corte vieram, também, todos os seus costumes, passando a ser mais asseados e aprenderam a utilizar modos e costumes, 
utilizando talheres e copos. Foram implantadas escolas, bibliotecas, teatro, a cidade do Rio de Janeiro foi urbanizada, abriram ruas e calçamento, o comércio doméstico floresceu. (SHIGUNOV NETO; MACIEL, 2008).

Gomes (2012) destaca que no Brasil Império (1822-1889), após a independência em 1822, na instalação dos trabalhos da Assembleia Constituinte, que elaboraria a Constituição, D. Pedro I chamou a atenção para a necessidade de uma legislação especial sobre a instrução pública e, assim, a Constituição de 1824 afirma a gratuidade da instrução primária para todos os brasileiros, mas foi somente depois de muitos debates sobre a educação popular que, em 15 de outubro de 1827, a Assembleia Legislativa votou em favor da primeira lei de instrução pública nacional no Império do Brasil.

Essa primeira instrução estabelecia que houvesse escolas de primeiras letras em todas as cidades, vilas e lugares populosos e, no ensino das primeiras letras, a Matemática estava presente: "primeiras letras" significavam, afinal, "ler, escrever e contar", mas cabe destacar que esta lei fazia distinção na educação para meninos e meninas, prevendo escolas separadas para os dois sexos.

O currículo para as escolas de meninos envolvia "ler, escrever, as quatro operações aritméticas, prática de quebrados, decimais e proporções, noções gerais de geometria, gramática da língua nacional, moral cristã e doutrina católica”, enquanto as escolas para meninas existiriam nas localidades mais populosas, eram dirigidas por professoras e em seu currículo eliminava-se a geometria e a prática de quebrados, incluindo-se o ensino de práticas importantes para a economia doméstica (GOMES, 2012).

Pinto (2005) relata que no Brasil, desde 1928, a velha tradição memorística e fragmentada do ensino tradicional de matemática já era alvo de críticas de um dos mais ilustres protagonistas da renovação, o catedrático e diretor do Colégio D. Pedro II, do Rio de Janeiro, professor Euclides Roxo, o qual advogava a junção da Aritmética, Álgebra e Geometria em uma única disciplina denominada Matemática. Pinto esclarece que o professor Euclides Roxo era um defensor do método heurístico e que veio a colaborar com a Reforma Francisco Campos (1931), enfatizando o raciocínio lógico voltado para a descoberta, no lugar da memorização de definições e uso abusivo de regras algorítmicas.

Silva (2005) explica que nas últimas décadas o ensino da Matemática no Brasil sofreu muitas mudanças significativas, relatando que nas décadas de 40 e 50 do século XX o ensino da Matemática se formata pela memorização e mecanização, também 
conhecido como "ensino tradicional", modelo onde se exigia do aluno que decorasse demonstrações de teoremas (memorização) e praticasse listas com enorme quantidade de exercícios (mecanização), contudo, está metodologia não revela resultados significantes.

Pinto (2005) relata a reforma de 1942, orquestrada pelo ministro Capanema, consagrando a divisão entre o ginásio e um segundo ciclo de três anos, com a opção entre o clássico e o científico, enfatizando o ensino humanístico clássico, dando destaque à formação moral e religiosa. Silva (2005) prossegue nesta trajetória relatando que nos anos 60 os currículos de matemática passaram por uma reformulação em consequência do reflexo do movimento da "Matemática Moderna", o qual relata Pinto (2005, p.2), se desencadeia em âmbito internacional e atinge não somente as finalidades do ensino, mas também “os conteúdos tradicionais da matemática, atribuindo uma importância primordial à axiomatização, às estruturas algébricas, à lógica e aos conjuntos”.

Na década de 1970 foram evidenciados o abstrato e o formal, sem objetivar as aplicações, como resultado de novos programas elaborados no espírito da Matemática Moderna e nos anos 80, buscou-se valorizar, na aprendizagem da Matemática, a compreensão da relevância de aspectos sociais, antropológicos, linguísticos, além dos cognitivos (Brasil, 1998), cuja valorização surgiu como resposta aos fracos resultados da aprendizagem da Matemática nas décadas anteriores.

Já nos anos 90, tem-se o chamado "ensino renovado", em face de se ter verificado que não era nas tarefas de cálculo que os alunos tinham os piores resultados, mas sim nas tarefas de ordem mais complexa, que exigiam algum raciocínio, flexibilidade e espírito crítico (SILVA, 2005). Para Silva (2005), em que pese os esforços empreendidos no sentido de propor mudanças no ensino da Matemática nos últimos anos de 1990, esta disciplina continua no imaginário dos alunos como a grande vilã dentre as áreas do conhecimento, sendo-lhe imputados os altos índices de reprovação dos alunos.

\section{O PRÉ-CONCEITO QUE RONDA A MATEMÁTICA}

Neto, Matos e Oliveira Junior (2012), defendem que a matemática seja a primeira ciência com a qual se tem contato na vida acadêmica e, desde os anos iniciais os números já nos são apresentados e, neste primeiro contato a matemática não apresenta nenhum tipo de desagrado ou incômodo, mas com o passar do tempo, os alunos vão aos poucos criando um tipo de preconceito com a disciplina que eles têm tanto contato, começando a 
identificar a matemática como uma disciplina difícil, "coisa de gênio" e/ou "coisa de louco" (p.1).

Os autores ainda chamam a atenção para que esse preconceito com a matemática é algo que já está enraizado na sociedade, sendo repassado de pais para filhos, dos mais velhos para os mais novos e onde a mídia tem um papel que reforça todo este preconceito ao evidenciar argumentos que contribuem com esse pensamento. Também destacam que essas ideias acabam por criar sentimentos adversos à aprendizagem Matemática, criando uma repulsa e aversão à Matemática nos jovens, o que se observa nos adolescentes nos anos finais do Ensino Fundamental e por todo o ensino médio, onde esses últimos possuem maiores índices de reprovação em Matemática ou matérias que eles consideram ter uma maior relação com ela, como a Física e a Química.

O fato é que crescemos ouvindo que a Matemática é uma disciplina difícil, que exige dedicação e muitos exercícios de fixação. Esta é uma concepção que ainda hoje permanece entranhada na mentalidade de muitos alunos e educadores, tanto que o fracasso do aluno encontra como uma das justificativas o fato dos conteúdos desta disciplina serem difíceis. Este fato é corroborado pelo estudo de Silveira (2002), para a qual existe um sentido pré-constituído evidenciado na fala dos alunos de que a Matemática é difícil.

O estudo realizado por esta autora teve como sujeitos professores de Matemática, cujas falas evidenciam uma realidade onde o aluno considera a disciplina como chata e misteriosa, que assusta e causa pavor e, consequentemente, este aluno sente receio da sua dificuldade por não a aprender. A autora revela que, como resultado de tantos sentimentos ruins que esta disciplina desperta no aluno, somando-se ao bloqueio em não dominar sua linguagem e não ter acesso ao seu conhecimento alia-se, ainda, o sentimento de repulsa pela Matemática.

Diante deste cenário se tem um verdadeiro "jogo de empurra", conforme destaca a autora: Os professores de matemática do ensino médio manifestaram o sentido de jogar a culpa do fracasso dos alunos nas professoras de séries iniciais, pelo fato de estarem despreparadas e por optarem pelo Curso de Magistério por não gostar de Matemática e para fugir dela. Este sentido de empurrar a culpa longe de si, faz emergir o sentido de que ensinar matemática também é para poucos, e que recai novamente no préconstruído, pois ensinar uma disciplina considerada difícil dá status ao professor, conforme pesquisa feita, e que me parece, o professor de matemática procura manter (SILVEIRA, 2002, p.9). 
Como se vê essa é uma relação que não é fácil, contudo, existem maneiras de desmistificar esse imaginário que ronda a disciplina de Matemática e uma das maneiras é buscar novas estratégias de abordagens, bem como a introdução de recursos metodológicos que possibilitem fazer das aulas algo mais atrativo e, assim, o conhecimento mais significativo.

Alguns autores defendem que as dificuldades encontradas na aprendizagem Matemática perpassam, também, pela capacitação dos professores para atuar com os conteúdos que integram o currículo desta disciplina. Para Camargo (2003), a falta de preparação dos professores perpassa, ainda, pelo pouco tempo que dispõem para dedicarse aos seus alunos e aos cursos de aprimoramento, pois tem uma carga de trabalho que, em média, é de 8 a 10 horas por dia.

\section{O ENSINO DA MATEMÁTICA}

O ensino da Matemática já vem sendo discutido há muito tempo no campo educacional. Em 1989, D’Ambrósio já se debruçava sobre esta questão e alertava para o fato de que o ensino desta disciplina não era dinâmico, se prendendo às aulas expositivas onde o quadro negro era o recurso mais utilizado e o professor o detentor do conhecimento, achando-se no direito de ensinar o que achava importante:

\footnotetext{
"Sabe-se que uma aula típica de matemática em nível de primeiro, segundo ou terceiros graus ainda é uma aula expositiva, em que o professor passa para o quadro negro aquilo que ele julga importante. $\mathrm{O}$ aluno, por sua vez cópia da lousa para o caderno e em seguida procura fazer exercícios de aplicação, que nada mais são do que uma repetição na aplicação de um modelo de solução apresentado pelo professor (D’Ambrósio, 1989, p.15).
}

Neste contexto, pode-se, ainda, afirmar que o aluno neste ambiente será levado a acreditar que a aprendizagem Matemática se dá através de um acúmulo de fórmulas e algoritmos, que estudar Matemática é simplesmente aplicar as regras transmitidas pelo professor, dando à Matemática o escopo de um corpo de conceitos verdadeiros, estático, incontestável. Incontestável por ser produto de uma criação mágica, de grandes gênios. Pensamento este que reflete não só a concepção do aluno, mas, também a do próprio professor, já que ainda muitos acreditam que é possível o ensino da Matemática a partir da transmissão de uma lista extensa de exercícios.

Essas discussões que permeiam o ensino da Matemática, assim como de todo o processo educacional, decorrem de alguns apontamentos considerados como entraves na história da educação brasileira, conforme explana Silva (2005). Krüger e Ensslin (2013) 
ao abordarem sobre o Método Tradicional e o Método Construtivista de Ensino no Processo de Aprendizagem, destacam que o método tradicional de ensino segue a concepção de educação bancária explicitada por Freire (1978), o qual afirmava ser aquela na qual o professor é o narrador e os alunos são os ouvintes, não havendo comunicação entre professor e aluno. Destacam que neste tipo de Educação não há saber envolvido, pois os professores são meros depositadores e os alunos receptores e, apesar de depositarem, transferirem e transmitirem valores e conhecimentos, os alunos não aprendem, eles apenas arquivam o que é transmitido pelo professor e, com esta metodologia de ensino não há o despertar da criatividade e do senso crítico por parte dos alunos.

Lima (2014, p.14) destaca que o "aluno das séries iniciais deve adquirir e desenvolver quatro competências básicas para que possa concluir com sucesso a primeira etapa de ensino, sendo elas: números e operações, grandezas e medidas, espaço e forma e tratamento de informações". Estimular o aluno para que obtenha um raciocino lógico, que pense e crie, relacione ideias, através de desafios, jogos, quebra-cabeças, problemas que despertem sua curiosidade, entre outros, é função da Matemática e, no que se refere ao professor que trabalha com esta disciplina, cabe buscar novas estratégias, novos recursos pedagógicos visando este estímulo. Nesse contexto, pode-se dizer que o grande desafio é fazer com que o aluno compreenda o seu papel na sociedade, de agente ativo e transformador da sua realidade, e a importância da Matemática no seu dia a dia, levandoo a refletir suas ações como aluno e cidadão.

\section{AS QUATRO OPERAÇÕES BÁSICAS DA ARITMÉTICA}

Para Souza (2010) são fundamentais a presença e o uso social das operações matemáticas elementares (adição, subtração, multiplicação e divisão), em nossa vida cotidiana. Porém, fora do ambiente escolar, poucas são as vezes em que recorremos a essa forma de cálculo, sendo raras às vezes em que colocamos as "contas no papel”, utilizarse, portanto, de mecanismos como a calculadora, o cálculo aproximado e do cálculo mental. O fato é que, como expressa Souza (2010), apesar das inúmeras críticas, o ensino das operações, tal como se observa na maioria das salas de aula, ainda se pauta em uma abordagem tradicionalista, se perdendo, assim, a possibilidade de matematização de situações práticas do cotidiano, aspecto fundamental da inserção das pessoas no processo formal de escolarização, especialmente no Ensino Fundamental, além do que, negligencia 
o fato de que a ação precede a operação, assertiva fundamental de um processo de ensino voltado para a formação dos conceitos em Matemática, como expressa Miguel (2005).

Acredita-se assim, que os conteúdos devem ser trabalhados interligados e não, como costuma acontecer, separadamente. Aritmética, álgebra e geometria devem caminhar constantemente juntas de uma maneira que se preocupe com o desenvolvimento intelectual do aluno. No sentido de buscar o entendimento sobre a causalidade dos fenômenos associados ao não-aprendizado de conteúdos de Matemática no Ensino Fundamental, somam-se contribuições das diversas áreas do conhecimento, as quais têm contribuído sobremaneira para as pesquisas em Ensino de Matemática e, em particular, pode-se destacar a Psicologia, como referencial para o entendimento dos aspectos mentais associados a esses fenômenos.

Existem inúmeros aspectos comuns entre o embasamento vigotskyano e a linguagem Matemática. Dentre os quais, destaca-se que para o primeiro a relação homem/mundo é mediada por sistemas simbólicos, enquanto a segunda é um complexo conjunto de sistemas simbólicos, dentre outras definições. Duval (2011), ao tratar da questão cognitiva dos modos de acesso aos objetos fala do papel das representações na construção da compreensão matemática, destacando que a análise do conhecimento tem sua atenção nos modos como se acessa aos objetos, ou seja, a representação que os objetos têm na aprendizagem matemática, o que, de conformidade com o autor, leva a oposição do modo de acesso direto, qualificado de "intuição", e modos indiretos que se voltam para os processos de formação, mobilizando sistemas que constituem as diferentes atitudes dos sujeitos humanos.

Em sua teoria, Duval explica que os registros de representações são maneiras típicas de representar um objeto matemático, e o sistema no qual podemos representar um objeto matemático, denomina-se, sistema ou registro semiótico, que é importante não somente por se constituírem num sistema de comunicação, mas também por possibilitarem a organização de informações a respeito do objeto representado. Portanto, nas atividades matemáticas se pode representar um objeto utilizando vários registros de representação e, segundo a sua teoria é a conversão das várias representações manifestadas sobre um objeto de estudo que possibilita a construção do conhecimento.

Para o autor, esta análise sempre se fez a partir da distinção epistemológica fundamental, devendo responder a três questões: 1) Temos acesso aos objetos independentemente das representações? 2) Qual a natureza da relação? e; 3) Quais são os 
sistemas de representações que permitem ter acesso ao objeto? Ao buscar responder as questões colocadas, Duval (2011) relata que temos acesso imediato e direto a tudo que está em nosso campo de visão, ou seja, tudo que se situam no campo perceptível multissensorial, portanto, aquilo que compõe a realidade circundante e, os que não estão fora desse campo nos fazem recorrer as representações decorrentes da memória ou as descrições que outros podem fazer. e uma percepção imediata possível. No primeiro caso, Duval alega ser a percepção imediata o ponto de partida de todo conhecimento e. no que diz respeito à segunda questão, está se volta para uma questão importante: a formação dos conceitos, levando a duas outras situações: primeiro, a maneira como a sua formação se articula com as representações nascidas da percepção, levando, por sua vez, a diferentes tipos de modelos cognitivos, seja como processo ascendente da abstração ou como processo inverso da esquematização, ou seja, do processo onde se dá a aplicação das primeiras noções à experiência sensível análoga à passagem das palavras às coisas.

No segundo caso, Duval nos relata que concerne à natureza da relação entre as representações e o objeto representado. Estamos falando aqui, dos signos, ou melhor, da relação que estes designam e que não pode ser definida em termos de causalidade, mas em termos de referência. Chegamos, portanto, na distinção entre "significante" e "significado". Mas, qual a importância desta distinção para o tema em estudo?

Considere-se que o termo representação aqui expresso diz respeito aos processos e produtos que são observáveis externamente como ocorrências internas nas mentes das pessoas que fazem matemática e, neste sentido, os programas escolares devem proporcionar às crianças, a criação e uso de representações para organizar, reunir e comunicar ideias matemáticas; a seleção, aplicação, e transformação de representações matemáticas para a resolução de problemas, o uso de representações para modelar e interpretar fenômenos matemáticos, físicos e sociais.

No atual Ensino da Matemática nem sempre a atenção se centra nas representações produzidas pelos alunos, incutindo-se formas de resolução de problemas rotineiros e dando-se mais ênfase à aprendizagem de processos formais em que pouco se considera a evolução do pensamento destes através dos seus próprios registros.

\section{RESOLUÇÃO DE PROBLEMAS}

A capacidade de resolver problemas é requerida nos mais diversos espaços de vivência das pessoas e, por isso, é considerada como uma habilidade fundamental, o que 
têm levado os programas que realizam avaliações para conhecer o nível de conhecimento matemático da população, organizarem seus testes contemplando a resolução de problemas como prioritária na avaliação, exemplo disto é o Sistema Nacional de Avaliação da Educação Básica - SAEB, que vem sendo aplicada desde 1990, através de testes e questionários, avaliando os estudantes brasileiros da $4^{\mathrm{a}}$ e $8^{\mathrm{a}}$ séries do Ensino Fundamental.

Maior e Trobia (s/d) relatam que a resolução de problemas vem a despontar como uma metodologia de Ensino no final da década de 80, quando começa a ter uma nova dimensão. Considera-se como um problema toda situação que pode ser problematizada, tais como: jogos, em que se busca uma estratégia para vencer, qualquer tipo de atividade planejada, levantamento e seleção de informações, qualquer atividade que requeira uma atitude investigativa.

Uma situação problematizada não se resolve simplesmente através de fórmulas ou aplicação de uma determinada regra, é necessária uma atitude de investigação mais profunda, onde a resposta encontrada não é mais importante do que o caminho percorrido para se chegar até ela. Parte-se, portanto, do princípio que o processo desenvolvido pelos alunos com essas representações poderá tornar a aprendizagem mais significativa para eles. Considerando que quando os alunos representam estão a exteriorizar aquilo que pensam e a forma como organizam essa informação, as representações dos alunos constituem um ponto de partida para a evolução e construção de conhecimento.

$\mathrm{Na}$ Resolução de Problemas como metodologia de ensino, os conceitos e as técnicas operatórias são apresentados aos alunos fazendo uma relação entre a ideia matemática e o contexto e, neste sentido, Diniz (2006) afirma que, a resolução de problemas é um caminho para se ensinar Matemática e nessa perspectiva, por meio da resolução de problemas, como ponto de partida, é possível introduzir novos conceitos, fazer a conexão com outros ramos da Matemática e iniciar novos conteúdos.

$\mathrm{Na}$ resolução de problemas, a comunicação é essencial, seja ela oral, escrita, ou através de desenhos. Isso possibilita ao professor, observar as mudanças de atitudes e acompanhar o progresso do aluno, bem como, interferir nas dificuldades encontradas, seja para o desenvolvimento das estratégias planejadas, ou mesmo para entender determinados conceitos. Pode-se dizer que os alunos ao resolverem problemas podem descobrir fatos novos, sendo motivados a encontrarem várias outras maneiras de resolverem o mesmo problema, despertando a curiosidade e o interesse pelos conhecimentos matemáticos e 
assim, desenvolverem a capacidade de solucionar as situações que lhes são propostas. Portanto, não é muito afirmar, ainda, que ao despertar no aluno o gosto pela resolução de problemas não é tarefa fácil, muitos são os momentos de dificuldade, obstáculos e erros. Isto acontece porque professores e alunos não conseguem distinguir um problema matemático de um exercício matemático.

Outro fator importante, que deve estar dentro do leque de preocupações de um professor durante a resolução de problemas, é se o aluno possui ou não pré-requisitos para execução do problema proposto. "É relativamente recente a atenção ao fato de que o aluno é agente da construção do seu conhecimento, pelas conexões que estabelece com seu conhecimento prévio num contexto de resolução de problemas" (PCN, 1998). Assim, devemos propor situações que os estudantes tenham condições de resolver. Caso contrário, poderemos estar nutrindo sentimentos de aversão à Matemática. O professor deve levar seu aluno a superar os procedimentos padronizados, próprios de uma didática desvinculada de situações reais, considerando a nova relação do aluno com o conhecimento adquirido na resolução de problemas.

\section{O ÁBACO COMO UM RECURSO DIDÁTICO}

O Ábaco, considerada como a primeira máquina de calcular conhecida pela humanidade, foi inventado pelos chineses, mas também a história registra instrumento similares criadas por japonêses, russos e aztecas. A versão chinesa pode ser encontrada num livro da dinastia Yuan do século XIV, sendo utilizado como recurso didático por professores na realização das operações básicas com números inteiros.

Como esclarece Souza (2017, p.2), “a Matemática em sua origem está relacionada às necessidades cotidianas como medir, pesar, entre outras que o homem realizava tendo em vista sua sobrevivência”. Contudo, esclarece Souza, com a ampliação das atividades humanas as representações utilizadas para calcular já não davam conta das grandes quantidades com as quais os homens trabalhavam, o que exigiu que os homens pensassem em novas formas de calcular, para além da representação um a um, para quantificar.

Desde a antiguidade existiu entre os homens a necessidade de controle e comunicação das quantidades, sendo esta necessidade que permite a compreensão do surgimento do ábaco como instrumento de contagem historicamente construído e, posteriormente visando atender a essa necessidade. 
Como destaca Silva (2014), quando o homem passa a pensar em uma maneira de contar e calcular, primeiramente ele parte do mundo, para em seguida, pôr em prática e, assim, concretizar a necessidade de controle das quantidades a partir do uso de vários objetos: pedras, conchas, nós e outros recursos que ajudaram na estruturação do pensamento matemático. Mas, é certo afirmar que essa necessidade não para por aí, pois que as atividades humanas com a evolução das sociedades se ampliam, portanto, é certo afirmar ainda, que as representações necessitavam mudar para atender quantidades cada vez maiores.

Como esclarecem Neves et al., (2017), o Ábaco é um dos primeiros dispositivos mecânicos computacionais, em suas versões primitivas já eram utilizadas desde 2500 a.C. no Oriente Médio e que seu nome deriva do grego abax ou abaikon, e em sua forma primitiva era composto de um tabuleiro com areia espalhada, onde eram feitos sulcos e colocados pedrinhas. Mas, como ressaltam Soares e Silva (2011, p.6239) a criança, igualmente os povos antigos também utilizam objetos e, através de sua manipulação vão assimilando a noção de quantidade.

Da mesma forma, a criança utiliza-se da manipulação de objetos no início da aquisição de habilidades para realizar operações aritméticas. Segundo os estudos do psicólogo suíço Jean Piaget (1983), a criança utiliza-se da manipulação de objetos no início da aquisição de habilidades em realizar operações aritméticas. É essa experiência com materiais concretos que lhe permite, posteriormente, o raciocínio abstrato, porém, não basta oferecer objetos concretos para que ela crie o conceito de contagem, é necessário envolvê-la em situações-problema que lhe permita raciocinar e também em atividades nas quais sejam possíveis as ações e reflexões que auxiliem a compreensão.

Neves et al., (2017) afirmam, ainda, que há vários tipos de Ábaco: o Suam Pan chinês, o Abacus romano, Abax grego, Nepohualtzitzin asteca, Soroban japonês, e o modelo russo. Estes autores afirmam, também, que o modelo chamado aberto é originário das tribos de Madagascar, que tinham o costume de 'contar' seus guerreiros fazendo-os passar um a um por uma passagem estreita e para cada um colocavam uma pedra em um buraco no chão e quando completava a quantia de dez guerreiros as pedras do buraco eram trocadas por uma única pedra, que correspondia a uma dezena, que passava a ser posta em outro buraco e assim iam fazendo até o total de dez dezenas, quando, então, trocavam por outra pedra, reiniciando a contagem até passar o ultimo guerreiro. 
Para Silva (2014), a evolução da sociedade dependeu das relações que foram estabelecidas entre si e as pessoas a partir da necessidade de sobrevivência e da busca de assegurar melhores condições de vida e o ábaco foi criado para atender a esses objetivos. Como defende a autora, o que em um primeiro momento parece um simples recurso, hoje é um recurso que é capaz de promover a compreensão do Sistema de Numeração Decimal (SND), já que a sua manipulação e uso pelos alunos promove a aprendizagem dos conhecimentos, sendo estes, a resolução de problemas de equivalência, valor posicional e decimal, a compreensão das quatro operações básicas, o que acaba por despertar no aluno o interesse pela Matemática.

Atualmente o ábaco e frequentemente utilizado no processo de ensinoaprendizagem no sistema de numeração decimal, sendo composto por uma base, argolas e quatro hastes utilizadas para representar as unidades, dezenas, centenas e unidades de milhar do sistema de numeração decimal. O ábaco de pinos é um material utilizado como recurso para os trabalhos de Matemática para desenvolver atividades envolvendo o Sistema de Numeração Decimal, na base 10 e o valor posicional dos algarismos, além de realizar operações matemática.

Estudos no âmbito da Educação Matemática como os defendidos por Silva, Coqueiro e Ceolim (2011) evidenciam que grande parte das pessoas não compreendem a Matemática em seu cotidiano, o que não é diferente do que ocorre na escola em relação ao professor e aluno durante os processos de ensino e aprendizagem. Nesta perspectiva, Sousa e Oliveira (2010, p. 1) destacam duas situações importantes: o desinteresse do aluno por não entender os conteúdos matemáticos trabalhados pelo professor em sala de aula e, também, o fato do professor, o qual vem aos poucos perdendo o prazer na prática docente em consequência das práticas pedagógicas que usa e que não vem despertando o interesse em seus alunos.

Assim, para a formação destes professores, Fiorentini e Lorenzato (2006) ressaltam que em sala de aula, o professor deve oferecer inúmeras e adequadas oportunidades para as crianças, para isso é necessário possuir materiais didáticos apropriados, as atividades a serem trabalhadas devem ser escolhidas de acordo com os objetivos da aula. Uma das tendências matemática com o intuito de mudar esse cenário de ensino apresentada na maioria das escolas, é a utilização de recursos didáticos no ensino e aprendizagem da matemática. 
Neste contexto, Gerhardt (2013) destaca que o ábaco pode ser indicado como uma estratégia para trabalhar a dificuldade que os alunos têm para construir o sistema de numeração decimal, pois facilita a compreensão de construir (composição e decomposição) do número a partir do valor posicional dos algarismos. Em geral este instrumento serve para estudar o sistema de numeração decimal, mas também pode servir como ferramenta para o estudo das operações com números inteiros. Neste contexto, Silva (2014, p.13) destaca que "o ábaco precisa estar aliado a outras estratégias didáticas, ao planejamento e as atividades em si, e, em especial, nas ações de ensino do professor", contudo, ressalta que este não é percebido nas aulas de matemática de modo significativo, apesar de colaborar com o processo de ensino e aprendizagem, não é usado adequadamente nas aulas de Matemática. Afirma, ainda, que uso do ábaco permite a construção da noção real do número inteiro, na passagem da unidade para a dezena, da dezena para a centena, da centena para a unidade de milhar, da unidade de milhar para a dezena de milhar etc., e, ainda ser usado para executar as operações de adição, subtração, divisão e multiplicação. Sugere-se, por fim, que o professor faça a utilização do ábaco no ensino das operações básicas envolvendo os números naturais, superando procedimentos padronizados, próprios de uma didática desvinculada de situações reais, contribuindo assim, para uma nova relação do aluno com o conhecimento adquirido através de resolução de problemas.

\section{CONCLUINDO}

O fracasso na aprendizagem da Matemática, segundo argumenta Melo (2021) se deve, em grande parte, ao fato de as atividades escolares serem desvinculadas das situações de vida dos alunos. A linguagem usada na escola não é a do aluno e a Matemática não faz sentido para ele, uma vez que o aluno não tem oportunidade de construir seus próprios conhecimentos.

O educador deve manter o olhar atento ao desenvolvimento individual e do grupo que está trabalhando no momento, pois as pessoas percorrem caminhos parecidos, mas em velocidades diferentes, de acordo com o meio em que vivem e principalmente dos estímulos que recebem dos adultos que os cercam. O desenvolvimento pessoal não é linear, as pessoas avançam, aparentemente param ou recuam, conforme seu estado emocional ou pela necessidade de rever uma hipótese para aprimorá-la. É conhecendo bem o seu grupo que o professor saberá se determinado conteúdo é adequado ou não. A 
Matemática está presente no dia a dia das pessoas, o que falta são estímulos para uma maior eficácia de seu ensino.

A escola precisa oferecer um espaço de experimentação e criação, estimulando um sentimento de cooperação e solidariedade, sabe-se que existem diferentes propostas de trabalho que possuem materiais com características muito próprias, e que os utilizam também de forma distinta e em momentos diferentes no processo ensinoaprendizagem. Como já referenciado, por trás de cada material, se esconde uma visão de educação, de matemática, do homem e de mundo; ou seja, existe subjacente ao material, uma proposta pedagógica que o justifica.

\section{REFERENCIAS}

BOYER, Carl Benjamin. - História da Matemática: tradução: Elza F. Gomide. São Paulo, Edgard Biucher, Ed. da Universidade de São Paulo, 1996.

BRASIL. Ministério da Educação e do Desporto. Secretaria de Educação Fundamental. Parâmetros Curriculares Nacionais: matemática. Brasília: MEC/SEF. 1998.

CAMARGO, Paulo. Quando o Problema não é o Aluno. Jornal folha da São Paulo. Disponível em https://www1.folha.uol.com.br/folha/sinapse/ult1063u723.shtml. Acesso em: 10 de julho de 2017.

D’AMBRÓSIO, Beatriz S. Como ensinar matemática hoje? Temas e Debates, SBEM, ano II, n. 2. 1989.

D’AMBRÓSIO, Ubiratan. Uma história concisa da matemática no Brasil. Petrópolis: Vozes, 2011.

DINIZ, M. I. (Org.) Ler, escrever e resolver problemas: habilidades básicas para aprender matemática. 1. ed. reimp. São Paulo: Artmed, 2006. p. 87-97.

DUVAL, Raymond. Ver e ensinar a matemática de outra forma: entrar no modo matemático de pensar: os registros de representações semióticas. Org. Tânia M. M. Campos. Trad. Marlene Alves Dias. São Paulo: PROEM, 2011.

FIORENTINI, Dario; LORENZATO, Sérgio. Investigação em educação matemática: percursos teóricos e metodológicos. - Campinas, SP: Autores Associados, 2006. (coleção Formação de Professores).

Investigação em educação matemática: percursos teóricos e metodológicos. 2ed. Campinas: Autores Associados, 2009.

FREIRE, Paulo. Pedagogia do oprimido. 6. ed. Rio de Janeiro: Paz e Terra, 1978. 
FONSECA, J. J. S. Metodologia da pesquisa científica. Apostila Fortaleza: UEC, 2002.

GERHARDT, Eliane. Descobindo a Matemática. Ábaco. Disponível em: http://descobrindoamatematica6na.blogspot.com.br. Acesso em: 10 de julho de 2017.

GOMES, Maria Laura Magalhães. História do Ensino da Matemática: uma introdução. Belo Horizonte CAED-UFMG 2012.

KRÜGER, Letícia M. \& ENSSLIN, Sandra R. Método Tradicional e Método Construtivista de Ensino no Processo de Aprendizagem: Uma Investigação com os Acadêmicos da Disciplina Contabilidade III do Curso de Ciências Contábeis da Universidade Federal de Santa Catarina. Organizações em contexto. São Bernardo do Campo, ISSNe 1982-8756 • Vol. 9, n. 18, jul.-dez.

LIMA, Cristiane Scheffer da Silveira de. As Dificuldades Encontradas por Professores no Ensino de Conceitos Matemáticos nas Séries Iniciais. (Monografia) Especialização em educação Matemática, Universidade do Extremo Sul CatarinenseUNESC. Criciúma, 2014.

MAIOR, Ludovico; TROBIA, José. Tendências metodológicas de ensinoaprendizagem em educação matemática: resolução de problemas - um caminho. s/d.

MELO, José Ronaldo. Desafios e possibilidades da utilização de jogos para o ensino de Matemática na Educação Básica. Conjecturas, vol. 21, no 3, p. 59-70, 2021.

MIGUEL, José Carlos. O Ensino de Matemática na Perspectiva da Formação de Conceitos: Implicações Teórico-Metodológicas. 2005, p. 387.

. et al. Algumas notas históricas sobre a emergência e a organização da pesquisa em educação matemática, nos Estados Unidos e no Brasil. A educação matemática: breve histórico, ações implementadas e questões sobre sua disciplinarização. Revista Brasileira de Educação. n. 27, p. 70-93, set.-dez., 2004.

NETO, João Freire Dantas; MATOS, Efraim de Alcântara; JÚNIOR, Carlos Magno Oliveira. Contribuições midiáticas para a construção do preconceito matemático. VII CONNEPI, Palmas, Tocantins, p. 01-06, 2012.

LIMA, Elisiane Santana de; LIMA, Wanderson Magno P. B. de. Ábaco: um recurso didático no ensino da adição e subtração de números naturais. Editora Realize. Disponível em https://www.editorarealize.com.br. Acessado em 28.10.2017.

PARANÁ. Departamento de Educação Básica. Secretaria de Estado da Educação do Paraná. Diretrizes Curriculares da Educação Básica Matemática. Curitiba: 2008.

PINTO, Neuza Bertoni. Marcas históricas da matemática moderna no Brasil. Revista Diálogo Educacional, Curitiba, v. 5, n.16, p.25-38, set./dez. 2005. HUNGLER, B. P. Fundamentos de pesquisa em enfermagem: métodos, avaliação e utilização. Trad. de Ana Thorell. 5. ed. Porto Alegre: Artmed, 2004. 
SHIGUNOV NETO, a.; MACIEL, L. S. B. O Ensino Jesuítico no Período Colonial. Educar, Curitiba, n. 31, p. 169-189, 2008. Editora UFPR. Acesso em: 10 de julho de 2017.

SILVA, Daniely Freitas. Ábaco como recurso para o ensino do sistema de numeração Decimal. (Monografia). Graduação em Pedagogia pela Universidade Estadual de Maringá, Paraná, 2014.

SILVA, José Augusto Florentino da. Refletindo sobre as Dificuldades de aprendizagem na Matemática: algumas considerações. Monografia, 2005. Disponível em https://repositorio.ucb.br. Acesso 10 de julho de 2017.

SILVEIRA, Marisa Rosâni Abreu. "Matemática é difícil": Um sentido pré-constituído evidenciado na fala dos alunos. 2002. Acesso em: 20 de outubro de 2017. Disponível em: http://www.ufrrj.br/emanped/paginas/conteudo_producoes/docs_25/matematica.pdf

SOUSA, Giselle Costa de; OLIVEIRA, José Damião Souza de. O uso de materiais manipuláveis e jogos no ensino de matemática. In: X ENEM - Encontro Nacional de Educação Matemática - Salvador, BA: UCSal, 2010.

SOUZA, Kátia do Nascimento Venerando de. As Operações de Multiplicação e Divisão nas Séries Iniciais do Ensino fundamental. (dissertação), Curso de Pedagogia, UNESP - Universidade Estadual Paulista Faculdade de Filosofia e Ciências - 17525-0900- Marília - SP, 2010.

SOUZA, S. E. O uso de recursos didáticos no ensino escolar. In: I Encontro de Pesquisa em Educação, IV Jornada de Práticas de Ensino, XIII Semana de Pedagogia da UEM: Infância e Práticas Educativas. Maringá-PR, 2007.

O USO DO ÁBACO NO ENSINO DA MATEMÁTICA: UMA EXPERIÊNCIA NA FORMAÇÃO EM NÍVEL MÉDIO DE DOCENTES. Ensino da Matemática em Debate (ISSN 2358-4122), [S.1.], v. 3, n. 2, p. 1-10, jan. 2017.

VYGOTSKY, L. S. Aprendizagem e desenvolvimento intelectual na idade escolar. In: VYGOTSKY, L. S.; LURIA, A. R.; LEONTIEV, A. N. (Org.). Linguagem, desenvolvimento e aprendizagem. São Paulo: Ícone, 1978, p. 57.

Recebido em: 15/09/2021

Aprovado em: 15/10/2021

Publicado em: 20/10/2021 